\title{
Regional and patient-related factors influencing the willingness to use general practitioners as coordinators of the treatment in northern Germany - results of a cross-sectional observational study
}

\author{
Heike Hansen ${ }^{* \dagger}$ (ID, Ingmar Schäfer ${ }^{\dagger}$, Sarah Porzelt, Agata Kazek, Dagmar Lühmann and Martin Scherer
}

\begin{abstract}
Background: In most countries, the general practitioner (GP) is the first point of contact in the healthcare system and coordinator of healthcare. However, in Germany it is possible to consult an outpatient specialist even without referral. Coordination by a GP might thus reduce health expenditures and inequalities in the healthcare system. The study describes the patients' willingness/commitment to use the GP as coordinator of healthcare and identifies regional and patient-related factors associated with the aforementioned commitment to the GP.

Methods: Cross-sectional observational study using a standardised telephone patient survey in northern Germany. All counties and independent cities within a radius of $120 \mathrm{~km}$ around Hamburg were divided into three regional categories (urban areas, environs, rural areas) and stratified proportionally to the population size. Patients who had consulted the GP within the previous three months, and had been patients of the practice for at least three years were randomly selected from medical records of primary care practices in these districts and recruited for the study. Multivariate linear regression models adjusted for random effects at the level of federal states, administrative districts and practices were used as statistical analysis methods.
\end{abstract}

Results: Eight hundred eleven patients (25.1\%) from 186 practices and 34 administrative districts were interviewed. The patient commitment to a GP attained an average of 20 out of 24 possible points. Significant differences were found by sex (male vs. female: +1.14 points, $p<0.001$ ), morbidity ( 0.10 per disease, $p=0.043$ ), education (high vs. low: $-1.74, p<0.001)$, logarithmised household net adjusted disposable income $(-0.93$ per step on the logarithmic scale, $p=0.004$ ), regional category (urban areas: $-0.85, p=0.022$; environs: $-0.80, p=0.045$ ) and healthcare utilisation (each GP contact: $+0.30, p<0.001$; each contact to a medical specialist: $-0.75, p=0.018$ ). Professional situation and age were not significantly associated with the GP commitment.

\footnotetext{
* Correspondence: h.hansen@uke.de

${ }^{\dagger}$ Heike Hansen and Ingmar Schäfer contributed equally to this work. Department of Primary Medical Care, University Medical Center Hamburg-Eppendorf, Martinistr, 5220246 Hamburg, Germany
} 
(Continued from previous page)

Conclusion: On average, the patients' commitment to their GP was relatively strong, but there were large differences between patient groups. An increase in the patient commitment to the GP could be achieved through better patient information and targeted interventions, e.g. to women or patients from regions of higher urban density.

Trial registration: The study was registered in ClinicalTrials.gov (NCT02558322).

Keywords: General practice, General practitioner-centred healthcare, Healthcare utilisation, Regional comparison, Urban-rural differences

\section{Background}

In most countries, healthcare is organised as a primary care system which usually means the general practitioner is also the first medical contact point in the healthcare system coordinating patients' healthcare across sectors [1-3]. This role of general medicine is also referred to as gatekeeping. Studies indicate that a well-functioning GP coordination might reduce, among others, healthcare spending and inequalities in the healthcare system [4-7].

In Germany, however, free choice of physician, ie, the possibility to consult a medical specialist without previous GP consultation, is upheld as a fundamental principle of medical care. Even so, the general practitioner is often the first contact point for a sick person and the specialist group of general practitioners is among the most frequently consulted groups of physicians in Germany $[1,8]$.

The so-called "commitment to a general practitioner" is a concept, investigating to what extent patients voluntarily use their GP's gatekeeping role or whether they move independently in the healthcare system instead. According to our definition, a strong commitment to a GP exists if 1) patients have a GP whom they prefer to consult first in all healthcare issues, 2) if patients understand their GP to be a central and competent coordinator of all their healthcare issues and 3) if there is a relationship of trust between patients and GP.

Regarding commitment to a GP, there seem to be vast differences between groups of patients and healthcare regions. This can be illustrated by models of the so-called "GP-centred healthcare" (HzV), which were introduced as special tariffs in Germany's statutory health insurances in 2004. By enrolling in $\mathrm{HzV}$, the participants commit themselves to consult a medical specialist only after referral by a contracted general practitioner [9]. Participation is voluntary for insured persons and GPs. The health insurance companies can offer the insured person advantages, eg, reduced co-payments in the pharmacies, but the $\mathrm{HzV}$ is not related to a different insurance premium than the normal tariff. There is a higher ratio of patients participating in $\mathrm{HzV}$ in less favoured rural areas. City dwellers, however, participate less frequently in $\mathrm{HzV}[10,11]$. Aside from the influence of the region where the patients live, participation in $\mathrm{HzV}$ is also associated with patient factors, eg, advanced age or existing chronic medical conditions [12].
However, it can be assumed that the commitment to a GP is probably not identical to the willingness to use $\mathrm{HzV}$. A major role whether patients with a strong commitment to a GP use $\mathrm{HzV}$ might play, for example, the tariff fixing by health insurances, GP's attitude towards $\mathrm{HzV}$, patients' data protection needs and psychological factors, such as individualism or general scepticism towards participating in interventions. The question, too, to what extent the long-time GP offers $\mathrm{HzV}$ or whether participating in $\mathrm{HzV}$ will only be possible by changing the GP, might influence participating in GP models independent of the commitment to a GP.

So far, the commitment to a GP as an independent concept has scarcely been investigated. The study presented here thus aims at describing the study population's commitment to a GP with an in-house developed measuring tool and investigating to what extent the residential region, patient factors, and use of GPs and medical specialists are associated with the commitment to a GP.

\section{Methods}

The study presented here is based on the cross-sectional observational study "Outpatient Healthcare Research North (Ambulante Versorgungsforschung Nord - AVFN)". The methods of this study had been entered in the study register ClinicalTrials.gov (NCT02558322) before starting the survey and described in the published study protocol [13]. Although our study has been based on GP and patient interviews, the analysis presented here includes patient data only. The results from the GP interviews are published elsewhere [14].

\section{Study regions and regional categories}

Three categories had been defined for the regional comparison based on the so-called "structural settlement of district types" of the German Federal Institute for Research on Building, Urban Affairs and Spatial Development [15]. The category "rural areas" included sparsely populated rural districts, the category "environs" urbanised districts and rural districts with signs of agglomeration, and the category "urban areas" independent large cities constituting districts in their own right.

For determining the survey area pursuant to the approach described in the study protocol [13], all 
administrative districts (counties and independent cities) were included in the study where at least $20 \%$ of the land area was located within a radius of $120 \mathrm{~km}$ (approx. 75 miles) linear distance around the study centre (University Medical Center Hamburg-Eppendorf). The thus chosen administrative districts for the study were derived from the German Federal States of Bremen, Hamburg, Mecklenburg-Western Pomerania, Lower Saxony, Saxony-Anhalt and Schleswig-Holstein. The specific districts and cities are shown in detail in the Tables A-C in Additional file 1.

\section{Recruitment of study participants}

The study participants' recruitment was carried out in two stages. At first, GPs were identified who had been accredited as statutory health insurance physicians in the respective administrative districts. This was achieved by using the database of the Department of Primary Medical Care at the University Medical Center Hamburg-Eppendorf as well as the databases of the respective regional associations of statutory health insurance physicians.

For the selection of GPs, a quota sampling design was chosen in order to be able to provide a representative picture of all regionally different healthcare situations in the study. The purpose of this design was to raise the probability of also including underserved regions into the study where usually many GPs were unwilling to participate in a study due to their heavy workload. The goal of the study was to recruit at least 80 GPs per regional category. The sample was stratified into individual administrative districts and the sample size in each district was fixed proportionally to the respective population size.

Subsequently, GPs thus identified were contacted in writing and invited to participate in the study. GPs were only eligible to participate in the study if they used an EDP system facilitating drawing up a list of all patients treated over the preceding quarter (3-month accounting period).

In stage two, every participating GP practice created a complete list from their electronic patient files of all patients who had been at least 18 years of age, had consulted the GP within the previous 3 months, and had been patients of the respective practice for a minimum of 3 years. Patients were randomly selected from this list and reviewed by the GP relating to the exclusion criteria until 15 eligible patients for the study had been identified and could be invited in writing to participate in the study. Patients were excluded if they had no capacity to give informed consent (eg, dementia), lacked German language skills and/or had functional limitations prohibiting a survey by telephone.

All participating patients signed a declaration of informed consent after they had received written and verbal information by their GP. The study was approved by the Ethics Commission of the Hamburg Medical Association on 12 August 2013 (file number PV 4535).

\section{Data collection and patient questionnaire}

The data was collected during the time frame of 13 July 2015 to 25 April 2017. The participating patients were interviewed by telephone using a standardised questionnaire. The questionnaire contained, among others, questions regarding sociodemographic factors, education and household income, state of health, frequency of contacts with GPs and medical specialists as well as commitment to the GP.

Education and vocational qualification were classified pursuant to the international CASMIN classification into three groups [16]: 1) low, ie, inadequately completed general elementary education or basic vocational qualification, 2) medium, ie, intermediate qualification or general maturity certificate, and 3) high, ie, lower or higher tertiary education. In order to facilitate a comparison between the study participants, the household income was equivalence-weighted, ie, divided by the number of household members by weighting the head of the household with "1", additional adult household members with " 0.5 " and children and young adults below the age of 15 years with " 0.3 ". The natural logarithm of the equivalised disposable income was calculated for the statistical inference analyses as a non-linear connection was assumed with the commitment to the GP.

Commitment to the GP was collected by using the questionnaire on intensity of the commitment to the GP ("Fragebogen zur Intensität der Hausarztbindung (F$\mathrm{HaBi})^{\prime \prime)}$. F-HaBi is a patient questionnaire examining the attitudes and behaviour regarding utilisation of GPs and medical specialists. It was developed at the Department of Primary Medical Care at the University Medical Center Hamburg-Eppendorf. The questionnaire is made up of six statements with the patient responding to each using the 5-step Likert scale as to what degree he agrees or disagrees. The patient's answers are combined into a total score between 0 to 24 points. Higher scores of the total score of commitment to the GP indicate that the patient more likely recognises and uses the GP as coordinator. Lower scores indicate that the patient prefers to move independently in the healthcare system. The F$\mathrm{HaBi}$ questionnaire is shown in the Additional files 2 (original German version) and 3 (English translation).

\section{Statistical analyses}

In the first step, data analysis was carried out using descriptive statistics. Chi-squared-tests and t-tests were carried out to analyse the differences of commitment to a GP between the regions and to describe the differences in sociodemographic data and the healthcare utilisation 
between patients with a strong and low commitment to their GP. In the process of analysing the difference regarding the commitment to the GP, the F-HaBi total score was dichotomised. Low commitment to the GP was assigned if the F-HaBi score was below the median and strong commitment to the GP was assigned if the score was equal to or above the median.

The correlation between residential region, patientrelated influencing factors, utilisation of GPs and medical specialists, and commitment to GPs was analysed using multivariate linear regression models adjusted for nested random effects at the levels of federal states, administrative districts and GP practices. The potential predictors of commitment to GPs were thus gradually included in three models. A possible improvement of the model fit by including additional variables compared to the next variable-reduced nested model was determined by the likelihood ratio test.

A psychometric validation was carried out to determine the suitability of the F-HaBi questionnaire. At first, the internal consistency of the construct with Cronbach's $\alpha$ was determined where $\alpha \geq 0.6$ was defined to be the threshold score for sufficient consistency. The onedimensional property of the construct was then tested with an exploratory factor analysis. Factors with an eigenvalue of $\geq 1.0$ were extracted. Items were assigned to a dimension (= a factor) if the factor loading was $\geq 0.3$. In a final step, the item-total correlation was determined with Pearson correlations between item scores and the Part-Whole-corrected summary score. The threshold score $r \geq 0.3$ was defined to be a satisfying item-total correlation.

Data processing and data analysis were carried out using Stata 15.1. An alpha level of 5\% $(p \leq 0.05)$ was defined to be statistically significant for all analyses of inferential statistics.

\section{Results}

\section{Patient recruitment}

With the included GP practices, 34 of the 37 selected administrative districts (91.9\%) could be displayed in the data set. A map of the respective regions can be found in Schäfer et al. 2020 [14]. Only three districts of the environs (Delmenhorst, Diepholz and Osterholz) could not be included into the study. At first, 280 GPs were recruited from the selected regions. However, no patients could be recruited from 65 GPs due to time-related or organisational reasons (eg, sick primary care partners, problems with the patient management software). In the end, the patients of a total of 215 GPs were selected and contacted.

Figure 1 shows the patients' recruitment process. During patient recruitment, each participating GP checked his patient list regarding exclusion criteria and excluded non-eligible patients. However, patient exclusion could not be documented in a structured way in 29 of the 215 practices due to the GPs' sometimes very heavy workload. In the remaining 187 practices, the GPs documented that 188 patients $(5.8 \%)$ were excluded due to functional limitations, 153 (4.7\%) due to missing capacity to consent and $84(2.6 \%)$ due to lacking language skills.

Altogether, 3225 patients from 215 practices were contacted by mail. Of those, there was no response from 1871 (58.1\%) patients, 504 (15.7\%) refused to participate, and 850 patients agreed to participate in the study. In the end, a total of 39 patients had to be excluded because the interview could not be carried out for different reasons (18 patients), the participation in the study had been withdrawn (16 patients) or it became clear during the telephone call that an exclusion criterion applied retrospectively ( 5 patients). In total, 811 patients (25.1\%) from 186 GP practices could be interviewed. Each of the aforementioned 34 administrative districts was represented by at least one participating GP practice and at least one interviewed patient. Tables $\mathrm{A}$ to $\mathrm{C}$ of the Additional file 1 describe the recruitment process of the stratification groups.

\section{Patient characteristics and the degree of commitment to the GP}

The sociodemographic data of the participating patients are listed in Table 1. On average, study participants had been 63 years of age and $58 \%$ of them female. Most of the patients had been from the region "rural areas". The majority of the population had general or intermediate qualifications and more than half of the study participants had already entered retirement. The average equivalised disposable income was approximately 1800 Euro per month. On average, patients suffered from five chronic medical conditions, had 1.9 times personal contact with their GP, and had consulted 0.6 times a medical specialist over the previous 3 months. High blood pressure, chronic back/neck pain and osteoarthritis were the most common medical conditions mentioned by patients (s. Table 2).

Table 3 shows the study participants' answers on the questionnaire regarding the degree of their commitment to their GP (F-HaBi). Between 81 and $95 \%$ of the patients agreed with "fully agree" or "mostly agree" to the first four more action-related statements concerning their GP commitment and $72 \%$ stated that they trusted their GP more than any other physician. $94 \%$ of them rated the GP information on their treatment as very good. Rural study participants stated more often than urban study participants to consult their GP in advance and get referrals from their GP before seeing a medical specialist. 


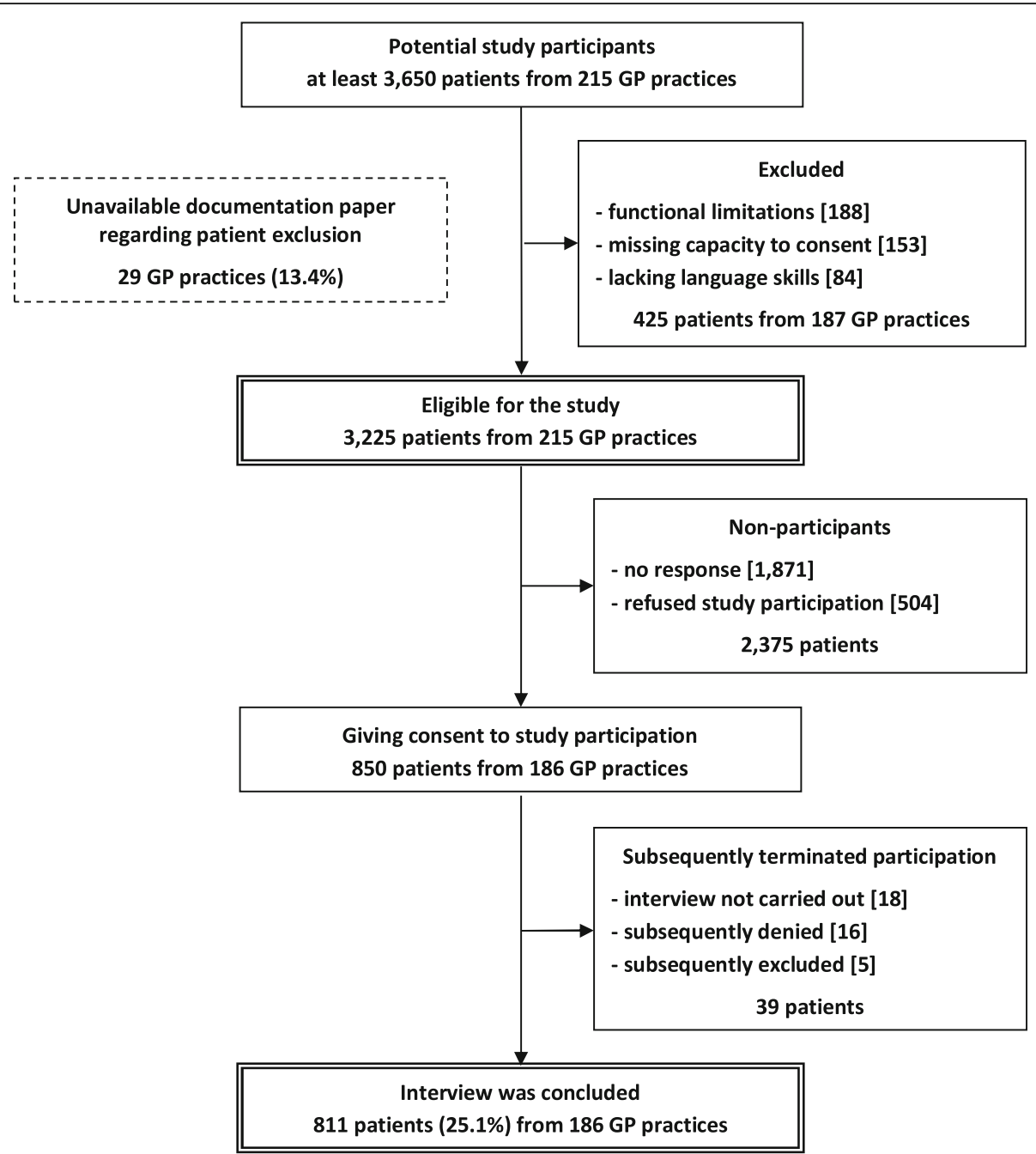

Fig. 1 Recruitment process in the patient population

The total score of commitment to the GP was in the arithmetic average of 20 points and in the median of 22 of 24 possible points. $51.2 \%$ of the patients had a commitment to their GP ranging between the median and maximum ("strong commitment to the GP"). $48.8 \%$ of the patients had a commitment to their GP below the median ("low commitment to the GP"). Comparisons of these two groups can be found in Tables 1 and 2. Patients with a stronger commitment to their GP were older and more likely male. They usually stated a lower income and more often had a lower and less frequently a higher education. In addition and more frequently, they had already been retired, were less likely to be an employee and were more often registered job-seekers.

Furthermore, patients with a stronger commitment to their GP had a higher number of chronic medical conditions. This involved in particular high blood pressure, diabetes mellitus, CHD, chronic fatigue, atherosclerosis/ PAOD and cardiac valve disorders. Patients with a stronger commitment to their GP had also more contact with their GP and less contact with medical specialists than patients with a lower commitment to their GP.

\section{Psychometric construct validation}

In the GP population described here, the six items with Cronbach's $\alpha=0.735$ showed an adequate high internal consistency. The explorative factor analysis showed with one single extracted factor (eigenvalue $=2.178$ ) the onedimensional property of the construct. At the same time, items 1 to 4 consistently showed a higher factor loading than items 5 and 6 (see Table 4). The item-total correlation could always be considered satisfactory with items 1 to 4 also consistently displaying a higher correlation coefficient than items 5 to 6 .

\section{Predictors of commitment to GP}

The correlation between region, sociodemography, healthcare utilisation and patients' commitment to their 
Table 1 Patient population according to degree of commitment to GP

\begin{tabular}{|c|c|c|c|c|}
\hline & In total $(n=807)$ & $\begin{array}{l}\text { Low commitment to GP } \\
(n=394)\end{array}$ & $\begin{array}{l}\text { Strong commitment to GP } \\
(n=413)\end{array}$ & $p$ \\
\hline Age (in years) & $62.8 \pm 13.8$ & $60.9 \pm 14.5$ & $64.7 \pm 12.9$ & $<0.001$ \\
\hline Sex & & & & 0.001 \\
\hline female & $57.7 \%$ & $63.7 \%$ & $52.1 \%$ & \\
\hline male & $42.3 \%$ & $36.3 \%$ & $47.9 \%$ & \\
\hline Regional category & & & & 0.176 \\
\hline urban areas & $28.1 \%$ & $31.0 \%$ & $25.4 \%$ & \\
\hline environs & $33.3 \%$ & $33.0 \%$ & $33.7 \%$ & \\
\hline rural areas & $38.5 \%$ & $36.0 \%$ & $40.9 \%$ & \\
\hline Education pursuant to CASMIN & & & & $<0.001$ \\
\hline low & $40.3 \%$ & $32.0 \%$ & $48.2 \%$ & \\
\hline medium & $43.5 \%$ & $45.0 \%$ & $42.1 \%$ & \\
\hline high & $16.2 \%(n=802)$ & $23.0 \%(n=391)$ & $9.7 \%(n=411)$ & \\
\hline \multicolumn{5}{|l|}{ Professional situation } \\
\hline retiree/pensioner & $54.5 \%$ & $47.7 \%$ & $61.0 \%$ & $<0.001$ \\
\hline employed & $30.3 \%$ & $36.4 \%$ & $24.3 \%$ & $<0.001$ \\
\hline self-employed/freelancer & $5.7 \%$ & $7.2 \%$ & $4.2 \%$ & 0.072 \\
\hline housewife/homemaker & $3.2 \%$ & $2.8 \%$ & $3.5 \%$ & 0.599 \\
\hline job-seeking/unemployed & $2.8 \%(n=793)$ & $1.5 \%(n=390)$ & $4.0 \%(n=403)$ & 0.037 \\
\hline Equivalised disposable income (in Euro per month) & $1795 \pm 877(n=786)$ & $1928 \pm 951(n=385)$ & $1667 \pm 779(n=401)$ & $<0.001$ \\
\hline $\begin{array}{l}\text { Number of chronic medical conditions (relating to } \\
39 \text { categories) }\end{array}$ & $4.9 \pm 3.3$ & $4.6 \pm 3.3$ & $5.3 \pm 3.4$ & $<0.001$ \\
\hline Number of contacts with GP (last 3 months) & $1.9 \pm 2.0(n=794)$ & $1.6 \pm 1.4(n=389)$ & $2.3 \pm 1.5(n=786)$ & $<0.001$ \\
\hline $\begin{array}{l}\text { Number of contacts with medical specialists } \\
\text { (last } 3 \text { months) }\end{array}$ & $0.60 \pm 0.49(n=806)$ & $0.64 \pm 0.48(n=394)$ & $0.56 \pm 0.50(n=412)$ & $<0.019$ \\
\hline
\end{tabular}

Statistically significant results $(p \leq 0.05)$ are shown in bolt and italic; Low commitment to GP = below the median; Strong commitment to GP = equal to or above the median

GP is illustrated in Table 5. Regarding the multivariate multilevel analysis, commitment to the GP in lower urban density was more pronounced in men and in cases of higher numbers of chronic medical conditions. This model did not verify a correlation with the patients' ages. This changed after including healthcare utilisation which, aside from identifying advanced age as predictor of a stronger commitment to the GP, also resulted in a significant improvement of the model fit $(p=0.002)$. Additionally, the patient's commitment to his GP was even stronger, the more contact he had with his GP and the less contact he had with medical specialists. In the end, the inclusion of income, education, and professional situation resulted in an additional significant improvement of the model fit $(p<0.001)$. However, age lost again its statistical significance in this model. On the other hand, tertiary education and a higher income were associated with a less pronounced commitment to the GP. The professional situation had no effect on the commitment to the GP in this model.

\section{Discussion}

\section{Main findings}

Commitment to the GP is a healthcare epidemiological construct for describing a patient's willingness to use the GP as coordinator of his medical treatment. The psychometric validation of a population of GP patients verified the commitment to the GP to be a one-dimensional construct with adequate high internal consistency und satisfactory item-total correlation of all items.

On average, the patients of the present investigation, who had all been recruited from systematically selected regions of northern Germany, attained relatively high scores regarding the total scores of commitment to their GP. However, there were clear differences according to sex, morbidity, education, income and degree of their residency's urban density. In fact, although age was identified to be a predictor for commitment to the GP, it lost, however, depending on the constellation of the model's enclosed covariates, its statistical significance. 
Table 2 Patient self-reported chronic conditions according to degree of commitment to GP

\begin{tabular}{|c|c|c|c|c|}
\hline & In total $(n=807)$ & Low commitment to GP $(n=394)$ & Strong commitment to GP $(n=413)$ & $p$ \\
\hline High blood pressure & $52.4 \%$ & $47.0 \%$ & $57.6 \%$ & 0.002 \\
\hline Chronic back pain/neck pain & $44.7 \%$ & $41.6 \%$ & $47.7 \%$ & 0.083 \\
\hline Osteoarthritis/mechanical arthritis & $42.1 \%$ & $39.6 \%$ & $44.6 \%$ & 0.154 \\
\hline Cutaneous nerve dysfunction & $27.0 \%$ & $28.7 \%$ & $25.4 \%$ & 0.298 \\
\hline High blood lipid levels & $24.8 \%$ & $22.6 \%$ & $26.9 \%$ & 0.158 \\
\hline Chronic sleep problems & $24.8 \%$ & $23.6 \%$ & $25.9 \%$ & 0.449 \\
\hline Dizziness/vertigo & $23.2 \%$ & $20.6 \%$ & $25.7 \%$ & 0.086 \\
\hline Thyroid disorders & $22.8 \%$ & $24.6 \%$ & $21.2 \%$ & 0.229 \\
\hline Chronic gastritis/gastro oesophageal reflux & $18.1 \%$ & $16.8 \%$ & $19.4 \%$ & 0.334 \\
\hline Severe visual problems & $16.7 \%$ & $16.2 \%$ & $17.2 \%$ & 0.718 \\
\hline Urinary incontinence/bladder weakness & $16.2 \%$ & $16.2 \%$ & $16.2 \%$ & 0.994 \\
\hline Heart arrhythmias & $15.6 \%$ & $14.7 \%$ & $16.5 \%$ & 0.495 \\
\hline Diabetes mellitus & $13.6 \%$ & $10.2 \%$ & $17.0 \%$ & 0.005 \\
\hline Depression & $11.8 \%$ & $10.9 \%$ & $12.6 \%$ & 0.460 \\
\hline Chronic fatigue & $9.9 \%$ & $7.6 \%$ & $12.1 \%$ & 0.033 \\
\hline Migraine/chronic headache & $9.9 \%$ & $11.4 \%$ & $8.5 \%$ & 0.161 \\
\hline Chronic skin conditions & $9.7 \%$ & $11.2 \%$ & $8.2 \%$ & 0.158 \\
\hline Heart diseases/CHD & $9.5 \%$ & $5.3 \%$ & $13.6 \%$ & $<0.001$ \\
\hline Somatoform disorders & $9.3 \%$ & $8.6 \%$ & $9.9 \%$ & 0.526 \\
\hline Enlarged prostate & $8.4 \%$ & $7.6 \%$ & $9.2 \%$ & 0.417 \\
\hline Anxiety disorders & $7.9 \%$ & $7.1 \%$ & $8.7 \%$ & 0.397 \\
\hline Asthma & $7.8 \%$ & $6.9 \%$ & $8.7 \%$ & 0.324 \\
\hline Malignant tumours & $7.7 \%$ & $6.6 \%$ & $8.7 \%$ & 0.259 \\
\hline Gynaecological problems & $7.3 \%$ & $7.6 \%$ & $7.0 \%$ & 0.747 \\
\hline Atherosclerosis/PAOD & $7.1 \%$ & $4.6 \%$ & $9.4 \%$ & 0.007 \\
\hline Increased susceptibility to infections & $7.1 \%$ & $5.3 \%$ & $8.7 \%$ & 0.061 \\
\hline Heart failure & $6.7 \%$ & $5.3 \%$ & $8.0 \%$ & 0.131 \\
\hline COPD/chronic bronchitis & $6.4 \%$ & $6.4 \%$ & $6.5 \%$ & 0.911 \\
\hline Rheumatoid joints/soft tissue rheumatism & $6.3 \%$ & $5.8 \%$ & $6.8 \%$ & 0.582 \\
\hline Elevated uric acid level/gout & $6.0 \%$ & $5.6 \%$ & $6.3 \%$ & 0.669 \\
\hline Osteoporosis & $6.0 \%$ & $4.3 \%$ & $7.5 \%$ & 0.055 \\
\hline Intestinal wall hernias/diverticula & $5.7 \%$ & $5.8 \%$ & $5.6 \%$ & 0.869 \\
\hline Status post stroke & $4.2 \%$ & $3.6 \%$ & $4.8 \%$ & 0.362 \\
\hline Liver diseases & $4.0 \%$ & $3.6 \%$ & $4.4 \%$ & 0.558 \\
\hline Cardiac valve disorders & $3.8 \%$ & $2.3 \%$ & $5.3 \%$ & 0.025 \\
\hline Renal failure/weak kidney function & $3.5 \%$ & $3.6 \%$ & $3.4 \%$ & 0.899 \\
\hline Gallstones/gallbladder inflammation & $3.2 \%$ & $3.1 \%$ & $3.4 \%$ & 0.782 \\
\hline Lack of red blood cells/anaemia & $2.5 \%$ & $2.5 \%$ & $2.4 \%$ & 0.915 \\
\hline Kidney stones/concrements in the ureter & $1.9 \%$ & $1.5 \%$ & $2.2 \%$ & 0.490 \\
\hline
\end{tabular}

Statistically significant results $(p \leq 0.05)$ are shown in bolt and italic; Low commitment to $G P=$ below the median; Strong commitment to $G P=$ equal to or above the median

Additionally, there was a correlation between the commitment to the GP and contacts to GPs and medical specialists. Due to the cross-sectional design of the study, it could not be clarified whether the commitment to the GP depended on healthcare utilisation or healthcare utilisation on the commitment to the GP. Thus, advocating the working hypothesis that the correlation is a two-way flow. 
Table 3 Patient self-report on commitment to GP from F-HaBi

\begin{tabular}{|c|c|c|c|c|c|c|}
\hline & Total & Urban areas & Environs & Rural areas & $p(u / r)$ & $p(e / r)$ \\
\hline When I have health problems, I visit my GP first. & & & & & 0.290 & 0.625 \\
\hline fully agree & $70.4 \%$ & $66.2 \%$ & $69.1 \%$ & $74.5 \%$ & & \\
\hline mostly agree & $24.7 \%$ & $28.5 \%$ & $26.0 \%$ & $20.7 \%$ & & \\
\hline not sure & $1.0 \%$ & $1.3 \%$ & $0.7 \%$ & $1.0 \%$ & & \\
\hline mostly disagree & $3.0 \%$ & $2.6 \%$ & $3.4 \%$ & $2.9 \%$ & & \\
\hline fully disagree & $\begin{array}{l}1.0 \% \\
(n=811)\end{array}$ & $\begin{array}{l}1.3 \% \\
(n=228)\end{array}$ & $\begin{array}{l}0.7 \% \\
(n=269)\end{array}$ & $\begin{array}{l}1.0 \% \\
(n=314)\end{array}$ & & \\
\hline $\begin{array}{l}\text { When I think that I have to see a medical specialist, } \\
\text { I consult my GP in advance. }\end{array}$ & & & & & 0.011 & 0.121 \\
\hline fully agree & $66.0 \%$ & $57.7 \%$ & $65.8 \%$ & $72.2 \%$ & & \\
\hline mostly agree & $19.9 \%$ & $25.6 \%$ & $17.1 \%$ & $18.2 \%$ & & \\
\hline not sure & $3.3 \%$ & $3.5 \%$ & $4.1 \%$ & $2.6 \%$ & & \\
\hline mostly disagree & $5.4 \%$ & $6.6 \%$ & $6.7 \%$ & $3.5 \%$ & & \\
\hline fully disagree & $\begin{array}{l}5.3 \% \\
(n=809)\end{array}$ & $\begin{array}{l}6.6 \% \\
(n=227)\end{array}$ & $\begin{array}{l}6.3 \% \\
(n=269)\end{array}$ & $\begin{array}{l}3.5 \% \\
(n=313)\end{array}$ & & \\
\hline I get a referral from my GP to see a medical specialist. & & & & & 0.006 & 0.012 \\
\hline fully agree & $67.0 \%$ & $59.7 \%$ & $65.4 \%$ & $73.6 \%$ & & \\
\hline mostly agree & $16.4 \%$ & $20.2 \%$ & $15.2 \%$ & $14.7 \%$ & & \\
\hline not sure & $2.8 \%$ & $4.0 \%$ & $1.5 \%$ & $3.2 \%$ & & \\
\hline mostly disagree & $6.8 \%$ & $9.7 \%$ & $7.8 \%$ & $3.8 \%$ & & \\
\hline fully disagree & $\begin{array}{l}7.0 \% \\
(n=811)\end{array}$ & $\begin{array}{l}6.6 \% \\
(n=228)\end{array}$ & $\begin{array}{l}10.0 \% \\
(n=269)\end{array}$ & $\begin{array}{l}4.8 \% \\
(n=314)\end{array}$ & & \\
\hline $\begin{array}{l}\text { I discuss the results of medical specialist consultations } \\
\text { with my GP. }\end{array}$ & & & & & 0.276 & 0.953 \\
\hline fully agree & $61.1 \%$ & $56.1 \%$ & $62.1 \%$ & $63.9 \%$ & & \\
\hline mostly agree & $19.9 \%$ & $22.4 \%$ & $20.1 \%$ & $17.9 \%$ & & \\
\hline not sure & $3.5 \%$ & $4.8 \%$ & $3.0 \%$ & $2.9 \%$ & & \\
\hline mostly disagree & $7.0 \%$ & $6.6 \%$ & $6.7 \%$ & $7.7 \%$ & & \\
\hline fully disagree & $\begin{array}{l}8.5 \% \\
(n=810)\end{array}$ & $\begin{array}{l}10.1 \% \\
(n=228)\end{array}$ & $\begin{array}{l}8.2 \% \\
(n=269)\end{array}$ & $\begin{array}{l}7.7 \% \\
(n=313)\end{array}$ & & \\
\hline I trust my GP more than any other physician. & & & & & 0.737 & 0.438 \\
\hline fully agree & $54.4 \%$ & $59.2 \%$ & $50.1 \%$ & $54.6 \%$ & & \\
\hline mostly agree & $17.9 \%$ & $16.2 \%$ & $20.5 \%$ & $16.9 \%$ & & \\
\hline not sure & $11.7 \%$ & $8.8 \%$ & $14.5 \%$ & $11.5 \%$ & & \\
\hline mostly disagree & $4.7 \%$ & $3.5 \%$ & $5.6 \%$ & $4.8 \%$ & & \\
\hline fully disagree & $\begin{array}{l}11.2 \% \\
(n=810)\end{array}$ & $\begin{array}{l}12.3 \% \\
(n=228)\end{array}$ & $\begin{array}{l}9.3 \% \\
(n=269)\end{array}$ & $\begin{array}{l}12.1 \% \\
(n=313)\end{array}$ & & \\
\hline My GP provides excellent information on my treatment. & & & & & 0.704 & 0.170 \\
\hline fully agree & $80.4 \%$ & $82.5 \%$ & $78.8 \%$ & $80.3 \%$ & & \\
\hline mostly agree & $13.8 \%$ & $12.7 \%$ & $14.9 \%$ & $13.7 \%$ & & \\
\hline not sure & $3.6 \%$ & $3.1 \%$ & $5.2 \%$ & $2.6 \%$ & & \\
\hline mostly disagree & $1.4 \%$ & $1.3 \%$ & $0.7 \%$ & $1.9 \%$ & & \\
\hline fully disagree & $\begin{array}{l}0.9 \% \\
(n=811)\end{array}$ & $\begin{array}{l}0.4 \% \\
(n=228)\end{array}$ & $\begin{array}{l}0.4 \% \\
(n=269)\end{array}$ & $\begin{array}{l}1.6 \% \\
(n=314)\end{array}$ & & \\
\hline
\end{tabular}


Table 4 Psychometric construct validation "commitment to GP" from F-HaBi

\begin{tabular}{lll}
\hline & Factor loading to extracted factor* & Item-total correlation** \\
\hline Item 1: When I have health problems, I consult my GP first. & 0.626 & 0.529 \\
Item 2: When I think that I have to see a medical specialist, I consult my GP in advance. & 0.815 & 0.662 \\
Item 3: I get a referral from my GP to see a medical specialist. & 0.734 & 0.578 \\
Item 4: I discuss the results of medical specialist consultations with my GP. & 0.587 & 0.533 \\
Item 5: I trust my GP more than any other physician. & 0.341 & 0.311 \\
Item 6: My GP provides excellent information on my treatment. & 0.351 & 0.340 \\
\hline
\end{tabular}

* Results of an exploratory factor analysis

** Results of Part-Whole-corrected Pearson correlations between items und summary scores

\section{Strengths and limitations of the survey}

One of our study's strengths is the fact that GP practices had been included via a quota sampling into the study. As a result, $91.9 \%$ of the administrative districts in the survey area could be illustrated and GPs of less favoured areas, such as Kalbe (Milde) or Helgoland, which are difficult to reach by public transport, could also be included into the study. However, in the end, we were able to interview only $25.1 \%$ of the patients contacted to participate in the study which might result in a limited representativeness of our patient sample.

The representativeness of our sample might also be affected by our eligibility criteria and the recruitment procedure. All participants of our study were exclusively from the regions of northern Germany so that our sample might possibly not represent the rest of Germany. The interviewed patients had been recruited through GP practices and our inclusion criteria selected patients who have been registered with their GP for at least 3 years and had seen their GP within the last 3 months. For that reason, the patients from our study probably had a higher commitment to their GP than the general population. It should also be noted that patients with relevant functional limitations regarding participation in the study, patients lacking German language skills and patients with missing capacity to consent could not be interviewed and that these patient groups were thus also not represented in the results presented here.

Table 5 Correlations between regions, sociodemography, healthcare utilisation and commitment to GP: results of a multivariate linear regression adjusted for random effects on the levels of German federal states, administrative districts and GP practices ( $n=$ 753)

$\frac{\text { Model } 1}{B(95 \% \mathrm{Cl})}$

$\frac{\text { Model } 2}{\beta(95 \% \mathrm{Cl})}$

Model 3

B $(95 \%$ Cl)

p

Region
urban areas vs. rural areas
environs vs. rural areas
Age (per 10 years)

Sex: male vs. female

Number of medical chronic conditions

Contacts with GP

Contacts with medical specialists

Education (pursuant to CASMIN):

medium vs. low

high vs. low

Equivalised disposable income: natural logarithm

Professional situation

employed

self-employed/freelancer

housewife/homemaker

job-seeking/unemployed

retiree/pensioner

$\begin{array}{ccc}-1.06(-1.81 /-0.31) & 0.006 & -1.05(-1.79 /-0.31) \\ -0.90(-1.74 /-0.07) & 0.034 & -0.96(-1.79 /-0.13) \\ 0.20(-0.04 / 0.43) & 0.098 & 0.28(0.05 / 0.51) \\ 1.09(0.48 / 1.70) & <0.001 & 1.02(0.42 / 1.62) \\ 0.17(0.08 / 0.27) & <0.001 & 0.15(0.05 / 0.25) \\ & & 0.33(0.17 / 0.49) \\ & & -0.86(-1.49 /-0.23)\end{array}$

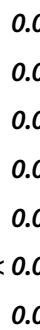

0.005

$-0.85(-1.58 /-0.12)$

$-0.80(-1.57 /-0.02)$

0.018

$0.25(-0.07 / 0.58)$

0.126

$0.001 \quad 1.14(0.53 / 1.74)$

$<0.001$

$0.003 \quad 0.10(0.00 / 0.20)$

0.043

$<0.001 \quad 0.30(0.15 / 0.46)$

$<0.001$

0.007

$-0.75(-1.36 /-0.13)$

0.018

$$
\begin{array}{ll}
-0.60(-1.29 / 0.08) & 0.086 \\
-\mathbf{1 . 7 4}(-\mathbf{2 . 6 8} /-0.81) & <0.001 \\
-\mathbf{0 . 9 3}(-\mathbf{1 . 5 6 / - 0 . 3 0 )} & \mathbf{0 . 0 0 4}
\end{array}
$$

$\begin{array}{ll}0.24(-1.04 / 1.52) & 0.714 \\ -0.57(-2.21 / 1.08) & 0.499 \\ 0.88(-1.11 / 2.88) & 0.385 \\ 0.73(-1.39 / 2.85) & 0.499 \\ 0.01(-1.45 / 1.46) & 0.993\end{array}$

Statistically significant results $(p \leq 0.05)$ are shown in bolt and italic 
There were no statistically significant differences regarding regional category, age, sex, workload and the total number of treated patients between GPs who recruited patients for our survey and GPs who failed to do so. We were unable to do a sample size calculation because this was an observational study with multiple outcomes. Therefore, we might have missed some differences between the regions due to limited statistical power. Despite the fact that the interviewers had received substantial training and had been supervised in regular meetings throughout the entire survey period, the patients' answers might - as in any other surveybased study, too, have been influenced by memory gaps, errors or social desirability. However, additional strengths worth mentioning are the applied statistical methods that also adequately facilitated taking potential confounders and the cluster structure of the dataset into account.

\section{Comparison with literature and discussion of results}

In a Forsa survey commissioned by the German association of national health insurances, $96 \%$ of 1000 participants stated to be very content or content with the healthcare provided by their GP [17]. A study by Detollenaere et al. exploring social differences in patient satisfaction of their GP within 31 European countries reported similar satisfaction rates [18]. The generally very high patient satisfaction with their GP in our survey might also be mirrored by the overall relatively strong commitment of the respective patients to their GP.

Compared to patients from rural areas, patients from urban areas clearly had a less pronounced commitment to their GP - predominantly regarding attaining and preliminary discussion for a referral. This finding might be explained, at least to a certain extent, by the regionally different number of medical specialists. A study conducted by the Robert-Koch-Institute, for example, showed that the density of psychotherapists varied 76-fold and the density of neurologists 17-fold between the individual regions of Germany [19]. GPs and patients realise that rural regions in particular are suffering from a undersupply of medical specialists [20]. Thus, 33\% of the surveyed patients from rural areas in the already mentioned Forsa study were very discontent with medical specialists' appointment allocations compared to $18 \%$ of patients surveyed in urban areas [17]. Other studies show similar results [21].

A study about predictors of having no GP by Tillmann et al. showed that the odds of having no GP significantly decreased with age and the presence of chronic conditions and increased for living in urban areas [22]. Vice versa, our study revealed higher commitment to the GP for patients from rural areas. Investigations of the $\mathrm{HzV}$ in Germany by Schnitzer et al. and Kürschner et al. report that older patients or retirees participate more often in GP models $[10,11]$. The age effect could not be clearly determined by our study because, depending on the statistical model, there was at times a correlation and then again no correlation with the commitment to the GP. The presence of medically diagnosed conditions and belonging to the social middle and lower class are linked to more willingness to participate in $\mathrm{HzV}$ [10]. The results of our investigation imply similar correlations with the commitment to the GP. Patients with lifestyle-associated medical conditions, such as cardiovascular conditions or diabetes, which occur more often in patients of lower socioeconomic status [23, 24], are particularly dependent on continuous (primary) medical care. Thus, the stronger commitment of these patient groups to their GPs is good news.

The European Social Survey (2014) show that higher educated participants were more likely to use health care specialists in 11 countries (UK, Sweden, Austria, Norway, Finland, the Czech Republic, France, Germany, Spain, Poland and Portugal) [25]. Schnitzer et al. report of a negative effect of tertiary education and urban residency in participating in $\mathrm{HzV}$ claiming that GP models can offset the more frequent utilisation of medical specialists by patients with a higher formal education in large cities [11]. Our analyses show a negative correlation between commitment to the GP and number of contacts with medical specialists. This implies that a likely increase in the commitment to the GP, eg, by participating in $\mathrm{HzV}$, may indeed have an effect on consulting medical specialists.

\section{Implications for research and clinical practice}

Considering age, sex, region of residency, morbidity and socioeconomic status, patients who showed a high degree of willingness to use their GP as coordinator of their treatment made somewhat more frequent use of their GP but considerably less use of medical specialists than patients with a low commitment to their GP. Bearing in mind that overuse and/ or misuse is all the more likely the more therapists a patient is consulting [26], using the coordinating function of the GP - as conveyed in the future positions ("Zukunftspositionen") of the German Association of General Medicine and Family Medicine (DEGAM) - might thus protect patients against "too much and the wrong medicine" [27].

Patients from regions with a higher urban density showed a lower commitment to their GP than patients from less-favoured regions. One explanation might be that urban patients are used to directly consulting medical specialists due to the large number of available medical specialists and the comparably short waiting times for appointments and therefore resort less to GP coordination.

Likewise, the lower commitment of women to their GP may be explained by the fact that they are often regularly cared for by gynaecologists and thus do not experience the GP as a central figure for coordinating the treatment. Additionally, the treatment coordination by a GP does not seem to be as appealing to those with a higher education and higher income and is therefore used less than by people with less income and a more remote education background. 


\section{Conclusions}

On average, the patients' commitment to their GP was relatively strong, but there were large differences between patient groups. $\mathrm{HzV}$ is an already existing and tested intervention for increasing the commitment to the GP $[10,11]$. Since, however, particularly the groups with the least commitment to a GP also have the lowest willingness to participate in $\mathrm{HzV}, \mathrm{HzV}$ in its present form seems to be least suited to appeal to the aforementioned patient groups.

A potential first starting point for increasing the commitment to a GP might be to provide the identified patient groups with specific information on the importance of GP coordination. In addition, qualitative studies with GPs and patients should explore how GP medical care can be made more appealing to patient groups like women or patients from regions of higher urban density, thus facilitating designing special GP models specifically focusing on groups with the lowest commitment to a GP.

\section{Supplementary information}

Supplementary information accompanies this paper at https://doi.org/1 0.1186/s12875-020-01180-3.

Additional file 1: Table A: planned and completed size in the region "urban areas". Table B: planned and completed sample size in the region "environs". Table $\mathbf{C}$ : planned and completed sample size in the region "rural areas".

Additional file 2. German version of the questionnaire on intensity of the commitment to the GP

Additional file 3. English version of the questionnaire on intensity of the commitment to the GP

\section{Abbreviations}

CASMIN: Comparative Analysis of Social Mobility in Industrial Nations; CHD: Coronary heart disease; COPD: Chronic obstructive pulmonary disease; DEGAM: German Association of General Medicine and Family Medicine; EDP: Electronic Data Processing; F-HaBi: Questionnaire on intensity of the commitment to the GP (Fragebogen zur Intensität der Hausarztbindung); GP: General practitioner; HzV: GP-centred healthcare (Hausarztzentrierte Versorgung); PAOD: peripheral arterial occlusive disease

\section{Acknowledgements}

We are grateful to the patients who participated in the study. We would like to express our appreciation to the numerous GPs who facilitated this study with their participation, namely: Karl-Heinz Aeffner, Volker Ahrens, Susanne Assmus, Ayhan Ayikli, Aina Barbakow, Hellmut Baur, Nina Becker, Gunter Behrend, Sven Behrens, Daisy Benson, Ulrich Berghof, Friederike Besch, Jürgen Biesewig-Siebenmorgen, Claudia Bleil, Karen Blumenbach, Eckart Boehnke, Ulrike Börgerding, Hans Böttcher, Marcus Brand, Jens Bräuer, Nicolay Breyer, Broder Brodersen, Peter Brümmer, Paola Brusa Düwel, Christian Butt, Kerstin Dann, Natascha Dannheisser, Susanne Dennig, Christian Dettmann, Björn-Ole Dieckvoß, Frank Döhling, Markus Dohrmann, Gero Domzig, Sabine Drengenberg, Thomas Drescher, Norbert Eckhardt, Henning Eggers, Jürgen Elis, Heike Elsen, Michael Emken, Susanne Faas-Ramm, Heino Feldbrügge, Matthias Fischer, Thomas Flasinski, Christiane Fock, Kurt Forstreuter, Dorothea Frederking, Dierk Freundl, Clemens Frey, Frank Fueting, Inka Führer, Michael Funke, Ralf Gade, Jan Geldmacher, Birgit Gier-Moser, Dagmar Gottkehaskamp, Daniel Graf, Inga Grimm, Carmen Cecilia Groninga, Peter Gründahl, Christine Gschwend, Nils Hansen, Henning Harder, Regina Hartwig-Haars, Ruth Hauck, Rudolf Hauschildt, Jürgen Hausmann, Henrik Heinrichs, Beate Heitmann, Rainer Hennecke, Franz Herrschel, Wolfgang Herzog, Corinna Hess, Ulrike Heye, Pamela Hilgenberg, Bernd Hinz, Andreas Hofinga, Herbert Hofstetter,
Karl Heinz Houcken, Charlotte Hübner-Urch, Peter Humbert, JanaHusemann, Claus Jaeckel, Markus Jäger-Rosiny, Heinz Jarmatz, Claudia Kahle, Lars Kämpfer, Stefan Kasischke, Dieter Kayser, Carlos Keller, Christiane Kindler-Behrens, Bernd Klemeyer, Michael Klemperer, Hans-Peter Knapp, Martina Koch, Dorothea Koersten, Stefan Köhn, Martin Kohne, Daniel Körbacher, Thomas Kötter, Toni Koudmani, Stefan Kreszis, Ute Lang, Raimund Leineweber, Nicole LenziSommer, Andreas Lindrum, Andrea Linsel, Thomas Loeseken, Daniel Lohmann, Margret Lorenzen, Berit Löwnau, Elisabeth Lübbers-Klare, Mirko Magens, Claudia Malchartzeck, Helmut Marczinkowski, Frank Meisel, Anne Meister, Albrecht Meister, Dagmar Menche, Wolf-Dieter Mengert, Hans-Georg Merkel, Ingo Migule, Andreas Mittelstädt, Eckart Möbius, Frank Möller, Rio Morawe, Mike Müller- Glamann, Karl-Christian Münter, Anila Nasery, KlausPeter Neizel-Tönnies, Marcus Netzel, Jonas Niemann, Birgit Obermeier, Michael Odinius, Swantje Ohlen, Ilse Ordemann, Irina Osinski, Christiane Otto, August Palatsik, Werner Petersen, Jürgen Pohl, Claudia Polay-Hehn, Uwe Pönnighaus, Dirk Rappenberg, Dirk Reese, Karin Rehder, Rainer Reiß, Friedel Rennekamp, Marlies Richter-Boehnke, Thomas Rohlfing, Ulrich Rose, Detlef Roshop, Anja Roß, Beatrice Roßbach, Janet Rossmann, Wolfgang Rumpf, Jörg Runge, Gerd Ruß, Detlef Schäfer, Peter-Andreas Schaper, Hans-Georg Schoermer, Manfred Schopf, Uta Schramm, Udo Schröder, Simon-Vitus Schuknecht, Walter Schulz, Susann Schütt, Jörg Schwarzkopf, Louis Sellier, Olaf Settgast, Helena Simov, Carsten Sommerfeld, Bettina Sponheim-Rambow, Maren Stadtlander-Rahm, Manfred Steinkohl, Andrea Stendel, Elke Sterling, HansHeiner Stöver, Ulrike Streit, Stefan Strzelec, Thomas Szlagowski, Georg Tacke, Gerrit Tarrach, Arjen Teetzmann, Silke Theisen, Jens Thomä, Bernd Thormählen, Sevine Tokdemir, Michael Topp, Matthias Trenkler, Thomas Tschirner, Christian Vahle, Martin Richard Vietor, Martina Vogler, Volker Voß, Meike Wagner, Jens Wagner, Doris Waller, Thomas Wasielewski, Jan Philip Wegner, Katrin Welke, Matthias Will, Sven-Ullrich Winter, Henning Winter, Delia Wirth, Lutz Witte, Anja Wittke, Thomas Wittke, Klaus Wogawa, Siegmar Zedler, Alexandra Zeidler, Eckhard Zeigert, Martin Zingel, Matthias Zink, Constantin Zoras and Nicole Zühlke.

\section{Authors' contributions}

MS, IS and HH conceived and designed the study. DL, SP and AK significantly contributed to the study design and/or discussion of the study results. IS analysed the data. HH and IS drafted the manuscript. All the authors commented on the draft and read and approved the final version of the manuscript.

\section{Funding}

The study was supported by the Hamburg and Schleswig-Holstein Association of Statutory Health Insurance Physicians. The funding body had no role in the design of the study and collection, analysis, and interpretation of data and in writing the manuscript.

\section{Availability of data and materials}

The datasets analysed during the current study are not publicly available as data sharing with other researchers was not part of patients' informed consent.

\section{Ethics approval and consent to participate}

The study was approved by the Ethics Commission of the Hamburg Medical Association on 12 August 2013 (file number PV 4535). All study participants gave their written informed consent prior to their participation in the study.

\section{Consent for publication}

Not applicable.

\section{Competing interests}

The authors declare that they have no competing interests.

Received: 24 February 2020 Accepted: 1 June 2020

Published online: 17 June 2020

\section{References}

1. Rattay P, Butschalowsky H, Rommel A, Prütz F, Jordan S, Nowossadeck E, et al. Inanspruchnahme der ambulanten und stationären medizinischen Versorgung in Deutschland. Bundesgesundheitsblatt, Gesundheitsforschung. Gesundheitsschutz. 2013;56:832-44. https://doi.org/10.1007/s00103-0131665-x

2. Larisch A, Heuft G, Engbrink S, Brähler E, Herzog W, Kruse J. Behandlung psychischer und psychosomatischer Beschwerden - Inanspruchnahme, 
Erwartungen und Kenntnisse der Allgemeinbevölkerung in Deutschland. Z Psychosom Med Psychother. 2013;59:153-69. https://doi.org/10.13109/zptm. 2013.59.2.153

3. Mack S, Jacobi F, Gerschler A, Strehle J, Höfler M, Busch MA, et al. Selfreported utilization of mental health services in the adult German population-evidence for unmet needs? Results of the DEGS1-mental health module (DEGS1-MH). Int J Methods Psychiatr Res. 2014;23:289-303. https:// doi.org/10.1002/mpr.1438

4. Greenfield G, Foley K, Majeed A. Rethinking primary care's gatekeeper role. BMJ (Clinical research ed). 2016;354:14803. https://doi.org/10.1136/bmj.i4803.

5. Gesetz zur Verbesserung der Versorgungsstrukturen in der gesetzlichen Krankenversicherung (GKV-Versorgungsstrukturgesetz (GKV-VStG)). Bundesgesetzblatt Teil l; 2011. p. 2983.

6. Schneider A, Donnachie E, Tauscher M, Gerlach R, Maier W, Mielck A, et al. Costs of coordinated versus uncoordinated care in Germany: results of a routine data analysis in Bavaria. BMJ Open. 2016;6:e011621. https://doi.org/ 10.1136/bmjopen-2016-011621

7. Zentner A, Velasco Garrido M, Busse R. Do primary care physicians acting as gatekeepers really improve health outcomes and decrease costs? A systematic review of the concept gatekeeping. Gesundheitswesen (Bundesverband Der Ärzte Des Öffentlichen Gesundheitsdienstes (Germany)). 2010;72:e38-44. https://doi.org/10.1055/s-0029-1234126 .

8. Thode N, Bergmann E, Kamtsiuris P, Kurth B-M. [predictors for ambulatory medical care utilization in Germany]. Bundesgesundheitsblatt, Gesundheitsforschung. Gesundheitsschutz. 2005;48:296-306. https://doi.org/ 10.1007/s00103-004-1004-3.

9. Klingenberg A, Broge B, Herholz H, Szecsenyi J, Ose D. Evaluation of special GP-centered health care contracts in Germany by the participating GPs. present situation and future perspectives. Medizinische Klinik (Munich, Germany: 1983). 2010;105:89-95. https://doi.org/10.1007/s00063-010-1012-8

10. Kürschner $\mathrm{N}$, Weidmann $\mathrm{C}$, Müters $\mathrm{S}$. Who enrolls in a general practitioner model? The behavioral model of health services use and general practitioner-centered care in Germany. Bundesgesundheitsbl Gesundheitsforsch Gesundheitsschutz. 2011;54:221-7. https://doi.org/10. 1007/s00103-010-1205-x

11. Schnitzer S, Balke K, Walter A, Litschel A, Kuhlmey A. [do gatekeeping programs increase equality of health care in Germany? A comparison of the health care situation of participants and nonparticipants].

Bundesgesundheitsblatt, Gesundheitsforschung. Gesundheitsschutz. 2011;54: 942-50. https://doi.org/10.1007/s00103-011-1317-y

12. Mehring M, Donnachie E, Schneider A, Tauscher M, Gerlach R, Storr C, et al. Impact of regional socioeconomic variation on coordination and cost of ambulatory care: investigation of claims data from Bavaria. Germany BMJ open. 2017;7:e016218. https://doi.org/10.1136/bmjopen-2017-016218.

13. Schäfer I, Hansen H, Pohontsch N, Bole L, Wagner H-O, Führ M, et al. Regional variation of patient behaviour and reasons for consultation in the general practice of northern Germany: protocol for an observational study. BMJ Open. 2016;6:e010738. https://doi.org/10.1136/bmjopen-2015-010738

14. Schäfer I, Hansen H, Ruppel T, Lühmann D, Wagner H-O, Kazek A, Scherer M. Regional differences in reasons for consultation and general practitioners' spectrum of services in northern Germany - results of a crosssectional observational study. BMC Fam Pract. 2020;21:1-12. https://doi.org/ 10.1186/s12875-020-1093-6.

15. BBSR Homepage - Siedlungsstrukturelle Kreistypen - Laufende Raumbeobachtung - Raumabgrenzungen. https://www.bbsr.bund.de/BBSR/ DE/Raumbeobachtung/Raumabgrenzungen/ SiedlungsstrukturelleGebietstypen/Kreistypen/kreistypen.html.

16. Brauns $\mathrm{H}$, Steinmann S. Educational reform in France, West-Germany and the United Kingdom: updating the CASMIN educational classification. ZUMA Nachrichten. 1999:23:7-44.

17. GKV-Versicherte sind mit der medizinischen Versorgung zufrieden. https:// www.vdek.com/magazin/ausgaben/2018-0102/titel-forsa-umfrage.html. Accessed 15 Jul 2019.

18. Detollenaere J, Hanssens L, Schäfer W, Willems S. Can you recommend me a good GP? Describing social differences in patient satisfaction within 31 countries. Int J Qual Health Care. 2018:30:9-15. https://doi.org/10.1093/ intqhc/mzx157

19. Rommel A, Bretschneider J, Kroll LE, Prütz F, Thom J. Inanspruchnahme psychiatrischer und psychotherapeutischer Leistungen - Individuelle Determinanten und regionale Unterschiede. J Health Monitoring. 2017. https://doi.org/10.17886/RKI-GBE-2017-111.2.
20. Hansen H, Pohontsch NJ, Bole L, Schäfer I, Scherer M. Regional variations of perceived problems in ambulatory care from the perspective of general practitioners and their patients - an exploratory focus group study in urban and rural regions of northern Germany. BMC Fam Pract. 2017;18:68. https:// doi.org/10.1186/s12875-017-0637-x

21. Albrecht M, Etgeton S, Ochmann RR. Faktencheck Gesundheit - Regionale Verteilung von Arztsitzen (Ärztedichte) - Haus-Kinder-, Frauen Und Augenärzte https://www.bertelsmann-stiftung.de/fileadmin/files/BSt/ Publikationen/GrauePublikationen/GP_Faktencheck_Gesundheit_ Aerztedichte.pdf. Accessed 18 Mar 2016.

22. Tillmann J, Puth M-T, Weckbecker K, Klaschik M, Münster E. Prevalence and predictors of having no general practitioner - analysis of the German health interview and examination survey for adults (DEGS1). BMC Fam Pract. 2019; 20:84. https://doi.org/10.1186/s12875-019-0976-x .

23. Kok R, Avendano M, Mackenbach JP. The association between socioeconomic status and changes in health in Europe. In: Borsch-Supan A, Brugiavini A, Jürges H, Kapteyn A, Mackenbach JP, Siegrist J, Weber G, editors. First Results From the Survey of Health, Ageing and Retirement in Europe (2004-2007): Starting the Longitudinal Dimension. Mannheim: Mannheim Research Institute for the Economics of Aging (MEA); 2008. p. 125-30.

24. Dalstra JA, Kunst AE, Borrell C, Breeze E, Cambois E, Costa G, et al. Socioeconomic differences in the prevalence of common chronic diseases: an overview of eight European countries. Int J Epidemiol. 2005;34:316-26. https://doi.org/10.1093/ije/dyh386

25. Fjær EL, Balaj M, Stornes P, Todd A, McNamara CL, Eikemo TA. Exploring the differences in general practitioner and health care specialist utilization according to education, occupation, income and social networks across Europe: findings from the European social survey (2014) special module on the social determinants of health. Eur J Pub Health. 2017;27:73-81. https:// doi.org/10.1093/eurpub/ckw255

26. Schoen C, Osborn R, How SKH, Doty MM, Peugh J. In chronic condition: experiences of patients with complex health care needs, in eight countries, 2008. Health Affairs (Project Hope). 2009;28:w1-16. https://doi.org/10.1377/ hlthaff.28.1.w1

27. DEGAM-Position Paper on the Future - Positions on the future of general practice and family medicine 2012. 2016. http://www.degam.de/files/ Inhalte/Degam-Inhalte/Ueber_uns/Positionspapiere/DEGAM-Position_Paper_ on_the_Future.pdf. Accessed 14 Jan 2016.

\section{Publisher's Note}

Springer Nature remains neutral with regard to jurisdictional claims in published maps and institutional affiliations.

Ready to submit your research? Choose BMC and benefit from:

- fast, convenient online submission

- thorough peer review by experienced researchers in your field

- rapid publication on acceptance

- support for research data, including large and complex data types

- gold Open Access which fosters wider collaboration and increased citations

- maximum visibility for your research: over $100 \mathrm{M}$ website views per year

At BMC, research is always in progress.

Learn more biomedcentral.com/submissions 